Canadian Journal of Civil Engineering

Canadian

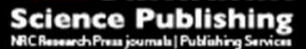

Revue canadienne de génie civil

\title{
Framework for Evaluating Risk of Limited Sight Distance for Permitted Left-turn Movements: Case Study
}

\begin{tabular}{|r|l|}
\hline Journal: & Canadian Journal of Civil Engineering \\
\hline Manuscript ID & cjce-2015-0498.R1 \\
\hline Manuscript Type: & Article \\
\hline Date Submitted by the Author: & $28-J a n-2016$ \\
\hline Complete List of Authors: & $\begin{array}{l}\text { Osama, Ahmed; University of British Columbia, Civil Engineering } \\
\text { Department } \\
\text { Sayed, Tarek; University of British Columbia, Department of Civil } \\
\text { Engineering } \\
\text { Easa, Said; Ryerson University, Civil Engineering }\end{array}$ \\
\hline Keyword: & Permitted Left Turns, Sight Distance, Reliability Analysis \\
\hline & \\
\hline
\end{tabular}

SCHOLARONE $^{\text {m }}$

Manuscripts 
Framework for Evaluating Risk of Limited Sight Distance for Permitted Leftturn Movements: Case Study

\author{
Ahmed Osama, M.Sc. (Corresponding Author) \\ PhD Student, Department of Civil Engineering \\ The University of British Columbia \\ 6250 Applied Science Lane \\ Vancouver, BC, Canada V6T 1Z4 \\ ahmed.osama@civil.ubc.ca
}

Tarek Sayed, PhD, P. Eng.

Professor, Department of Civil Engineering

University of British Columbia

6250 Applied Science Lane

Vancouver, BC, Canada V6T 1Z4

tsayed@civil.ubc.ca

Said Easa, PhD, P. Eng.

Professor, Department of Civil Engineering

Ryerson University

350 Victoria Street

Toronto, Ontario, Canada M5B 2K3

seasa@ryerson.ca

Word Count: $5357+9$ Figures +2 Tables 


\section{ABSTRACT}

A reliability analysis framework is used to evaluate the risk of limited Sight Distance for permitted left-turn movements due to the presence of opposing left-turn vehicles. Two signalized intersection approaches in the city of Surrey were used as case studies for the framework. Geometric and traffic video data was collected and analyzed using a computer vision tool to extract the input variables probability distributions. The data was used in the reliability analysis where first-order and importance sampling methods were performed. The analysis showed that the probability of non-compliance was considerable at one approach due to its large left-turn lane offset. The analysis also showed that the probability of non-compliance increased substantially when the obstacle vehicle was a bus rather than a passenger car. Moreover, the time gap had a higher impact on the probability of non-compliance compared to speed. Strategies were suggested to overcome the high probability of non-compliance.

Keywords: Permitted Left Turns, Sight Distance, Reliability Analysis. 


\section{INTRODUCTION}

Permitted left-turn phasing is commonly used at many signalized intersections in North America to reduce left-turn vehicle delay. In this phasing, left-turn movements are allowed after yielding to conflicting traffic and pedestrians. However, using permitted left-turn phasing can increase the potential for vehicle-vehicle and vehicle-pedestrian conflicts. This potential for traffic conflicts is particularly higher in the presence of opposing left-turn vehicles that reduce the available sight distance (SD), making it difficult for the driver to observe acceptable gaps to complete left turns safely (Joshua and Saka 1992). Several studies have evaluated the safety impact of using permitted left-turn phasing compared to protected-only left-turn phasing (Schultz 2014; Srinivasan 2012; Davis 2007). This is usually undertaken by developing collision modification factors (CMFs) which are multiplicative factors, generally based on empirical evidence from time series (i.e., observational before-after studies) or cross-sectional analysis of the safety impacts of individual geometric design and traffic control features. Developing CMFs for limited $\mathrm{SD}$ can be challenging as it is difficult to measure the safety in terms of collision reduction because of lack of data or difficulty isolating the impact of a single design element that has varying dimensions (i.e., sight distance) on collision frequency.

In these situations, reliability analysis can be used to evaluate the risk associated with a particular design feature. The principles used in this analysis follow the limit-state design approach. In this approach, the variables in the performance function are treated as random variables and are expressed as probability distributions rather than single values. In the limit-state approach, when 
the demand exceeds the supply, the system is considered to have failed or not complied with the system supply (capacity). There is a probability that the supply will be exceeded by the demand from the driver/vehicle combination.

Only one study has attempted to quantify the safety risk of limited SD for permitted left-turn movements (Hussain and Easa 2015). The study used First Order Second Moment Method (FOSM) for the reliability analysis of left turn vehicles. The purpose of the current paper is twofold: (1) to present a framework for evaluating the risk of limited SD for permitted left-turn movements based on the advanced First Order Reliability Method (FORM) and Importance Sampling and (2) to illustrate its application using a detailed case study that incorporates automated video analysis. The analysis estimates the probability of failure (non-compliance) for limited left-turn SD due to an opposing left-turn obstructing vehicle using two methods; The following sections present a literature review and the proposed methodology. Data collection, analysis and proposed strategies are then presented, followed by the conclusions.

\section{PREVIOUS WORK}

Sight distance for left-turn vehicles has been discussed in several studies. The safety of permitted (unprotected) left-turns is directly affected by SD availability (McCoy et al. 1999). According to AASHTO, the SD criterion for left-turn movements depends on the gap-acceptance concept (AASHTO 2011), which is based on observing the behavior of the driver entering the intersection. The gap-acceptance principle implies that for left-turn drivers to accept a specific 
critical gap on a major-road and for such maneuver to be undertaken safely, adequate intersection SD should be provided (Harwood et al. 1996). Relationships were developed to calculate available and required SD for left-turn vehicles (McCoy et al. 1999). There are number of factors that can affect the left-turn SD such as: location of the turning and opposing vehicles, vehicle dimensions, lane and median widths, vertical and horizontal alignments of the intersection approaches, and the offset distance between the opposing left-turn vehicles (McCoy et al. 1999).

AASHTO (2004) suggested improving left-turn SD by increasing lane width or using parallel/tapered offsets. Strong correlation was found between the offset distance from the leftedge of the left-turn lane to the right-edge of the opposite left-turn lane, and the available sight distance for the left-turn traffic (Easa and Ali 2005). Guidelines were first developed for the offset distributions that can give sufficient SD for left-turn movements in signalized intersections at different vehicle positions (McCoy et al. 1992; Tarawneh and McCoy 1997). Later, modified analytical guidelines were developed for the left-turn lane geometry, offset, length, and lane-line width to provide adequate SD for the left-turn vehicles and overcome the shortcomings of the former guidelines which used to underestimate the left-turn lane requirements and overestimate the available SD (Easa and Ali 2005). The modified guidelines are applicable to intersections with stop control on the minor road, and to signalized intersections with permitted left turns from an exclusive left-turn lane. 
Current road design guides offer a deterministic approach for design requirements which are based on conservative percentile values for the design inputs to account for uncertainty (Ismail and Sayed 2010). However, most of the design inputs (e.g. design speed), model parameters (perception reaction time), and model form (e.g. calculation of available sight distance) are associated with considerable uncertainty. Moreover, road design standards deal with road userrelated variables as constant parameters ignoring the fact that users adapt to the roads differently (Hauer 1999). The selection of the percentile values for the uncertain parameters is not usually based on specific safety measures which causes the safety margin of the design output to be largely unknown (Ismail and Sayed 2010). Moreover, existing road design guides offer little information on the safety implication of deviating from road design standards.

To mitigate these shortcomings, reliability analysis has been advocated by several researchers to account for the uncertainty in the road design process. Several applications exist for reliability analysis in transportation engineering which include: intersection SD (Easa 2000); evaluation of SD restrictions on horizontal curves (Richl and Sayed 2006; Sarhan and Hassan 2009); design of intergreen intervals at signalized intersections (Easa 1993; Tang et al. 2011); safety performance functions that incorporate probability of non-compliance as a design risk measure (Ibrahim and Sayed 2011); optimization of highway cross sections to minimize design risk (Ibrahim et al. 2012); risk evaluation of passing SD standards (Llorca et al. 2014); and geometric design code calibration (Ismail and Sayed 2009; Hussein et al. 2014).

In reliability analysis, a limit state function is structured to evaluate the probability of failure (usually termed probability of non-compliance in transportation applications). The limit state 
function is usually expressed as the difference between the supply and demand of a design element. Non-compliance occurs when the demand exceeds supply. Different reliability analysis methods can be used to calculate the probability of non-compliance. These include analytical methods such as the First Order Second Moment Method (FOSM) and the First Order Reliability Method (FORM); and sampling methods such as Monte Carlo and Importance Sampling.

FOSM is acknowledged to be the simplest reliability analysis method but it has several shortcomings. First, the limit state function in FOSM is approximated at the mean. This leads to the invariance problem, in which alternative formulations of the limit state function give different probabilities of non-compliance (Melchers 1999). As well, FOSM also assumes that the input parameters are normally distributed. FORM analysis has several advantages as it is conducted in a transformed space, where all variables are represented from their original distributions to a standard normal distribution. Moreover, in FORM analysis, the first-order linear expansion is performed at the design point, which is more accurate than performing it at the mean values. FORM also enables the designer to examine sensitivity to design inputs. The use of FORM analysis can be very efficient for smooth and differentiable limit state functions. Monte Carlo simulation offers a robust approach to calculate the probability of non-compliance but it does not produce the sensitivity to different design inputs and it can be computationally expensive to perform sampling evaluation of these sensitivities. Importance Sampling can give accurate results for the probability of non-compliance using smaller sample size than Monte Carlo method because it builds on the results from FORM analysis (Melchers 1999). 


\section{METHODOLOGY}

The probability distribution of the design input vectors can be represented by the joint probability distribution of its variables. As discussed earlier, the limit state function $(\mathrm{g}(\mathrm{X}))$ is the difference between the demand (R) and supply (S) of a system, where failure occurs to the system when the demand exceeds the supply. Variables in the limit state functions are treated as random variables and are represented by probability distributions rather than single values whenever applicable. The probability of non-compliance $\left(\mathrm{P}_{\mathrm{nc}}\right)$ is the integration of the design inputs variables joint probability over the domain, where the limit state function is less than zero $(\mathrm{g}(\mathrm{X}) \leq 0)$ as shown in equation 1.

$P_{n c g(x \leq 0)}=\iint f_{R}(r) f_{S}(s) d(r) d(s)$

FORM analysis is performed to evaluate $\mathrm{P}_{\mathrm{f}}$, where $\mathrm{y}^{*}$ is the most likely design point and represents the closest point coordinates to the origin on the hyperplane $g(x)=G(y)=0$. This hyperplane represents the limit state function in the standard normal space. The design point can be estimated according to (Harr 1987) by solving the optimization problem represented in equation (2).

$y^{*}=\operatorname{argmin}\{\|y\|$ such that $G(y)=0\}$ 
After obtaining the design point, the probability of non-compliance $\left(\mathrm{P}_{\mathrm{nc}}\right)$ and its sensitivity to design inputs $\left(\Delta \mathrm{P}_{\mathrm{nc}} / \Delta \mathrm{x}\right)$ can be directly estimated as shown in Equation 3 (Faghiri and Demetsky 1988), where $\nabla \mathrm{G}\left(\mathrm{y}^{*}\right)$ is the gradient of the limit state function at the design point.

$P_{n c}=\Phi\left(-y^{*}\right), \quad \frac{\Delta P_{n c}}{\Delta x}=-\frac{\nabla G\left(y^{*}\right)}{\left\|\nabla G\left(y^{*}\right)\right\|}$

Importance Sampling can be performed after FORM analysis to raise the accuracy of the reliability analysis results. The design point extracted from FORM is the center for the upcoming sampling distribution. Equation 4 shows the function used for calculating the probability of noncompliance in importance sampling (Melchers 1999), where I=1 for realizations when limit state function $\mathrm{g}(\mathrm{y})<0$, and 0 elsewhere; $\mathrm{h}(\mathrm{y})$ is the shifted standard normal probability distribution as illustrated in equation 5; and $\Phi(y)$ is the joint standard normal probability distribution function as shown in equation 6 .

$P_{n c}=\iint_{-\infty}^{\infty}\left(I(y) \frac{\Phi(y)}{h(y)}\right) h(y) d y$

$h(y)=\frac{1}{2 \pi^{n / 2}} \exp \left(-\frac{\left(y-y^{*}\right)^{T}\left(y-y^{*}\right)}{2}\right)$

$\Phi(y)=\frac{1}{2 \pi^{n / 2}} \exp \left(-\frac{y^{T} y}{2}\right)$ 
The sample size needed for sampling analysis is determined according to the required accuracy of the process. This is determined using the coefficient of variation $\left(\delta_{P f}\right)$ as shown in equation 7 , where $\mathrm{N}$ is the number of samples. An accurate sampling analysis is known to have a coefficient of variation less than $2 \%$.

$\delta_{P f}=\sqrt{\frac{1-P_{n c}}{N \cdot P_{n c}}}$

Figure 1 summarizes the framework that was used for evaluating the non-compliance probability of attaining sufficient SD for permitted left-turn movements. First, intersection geometry measurements, along with speed and time gap data of the intersection through traffic were collected. The geometric measurements are necessary to calculate the available SD which represents the supply in the limit state function (LSF). Speed and time gap data were collected through automated analysis of the recorded video data, and their probability distributions were used to evaluate the required SD which represents the demand in the LSF. A computer vision tool was used for the automated video analysis, where the process included camera calibration, features tracking, features grouping, and trajectories screening (Saunier and Sayed 2007). The reliability analysis included First Order Reliability Method (FORM), followed by Importance Sampling. The analysis framework is discussed further in the upcoming sections. 


\section{DATA COLLECTION}

A 4-leg signalized intersection (72nd Avenue and 132 St.) in the city of Surrey, British Columbia is used as a case study. Traffic video data were collected for 12 hours at two approaches of the intersection and the data were analyzed using computer vision techniques to obtain the parameters for the reliability analysis. Figure 2 shows the left-turn movements, camera positions, and the positions of obstacle vehicles at both approaches, along with an image of an actual leftturn collision that occurred on the studied intersection due to limited SD.

\section{Demand Variables}

The sight distance required for left-turn vehicles is the distance traveled by an approaching vehicle at major road design speed for an appropriate time gap (AASHTO 2011). The required sight distance for left-turn vehicles can be calculated according to Equation 8, where $\mathrm{V}$ is the vehicles' speed on major road in kilometer per hour, and G is the time gap between vehicles on major road in seconds (Harwood et al. 1996).

$S D_{\text {required }}=0.278 \mathrm{VG}$

Previous studies showed that the probability distribution of the traffic speed on road segments tends to be normally distributed (Sahoo et al. 1996; Dey 2006; Hou et al. 2012; Ni and Li 2014), while the time gap probability distribution tends to be log-normally distributed (Ragland et al. 2006; McGowen and Stanley 2011; Abtahi 2011; Moridpour 2014). Accordingly, for the 
reliability analysis in this study, the probability distribution of through vehicles speed on major road was assumed normally distributed and the time gap was assumed log normally distributed. The two distribution assumptions were verified using the chi-squared test, which showed a significant goodness of fit at the $99 \%$ level between the input data and the assumed distributions.

The data necessary to define the two distributions were automatically collected, where a computer vision tool was used for tracking road users in the recorded video data (12 hours for each of the studied approaches) based on feature-tracking algorithm (Saunier and Sayed 2006; Saunier and Sayed 2008). The tracking accuracy for the algorithm was measured on three different data sets and the results showed accuracy between $84.7 \%$ and $94.4 \%$ (Saunier and Sayed 2006; Saunier and Sayed 2007). The accuracy was evaluated by estimating the rate of true matches compared to the rates of false negative, over-grouping, false positive, and oversegmentation. A true match was defined as a matching between a vehicle and a group of features. An over- grouping was counted if a group of features matches more than one vehicle. Each of the false negative and the false positive were defined as an unmatched group. An over-segmentation was counted if a vehicle matches more than one features group. The overall results were satisfying, with an average percentage of correctly detected vehicles (true match) of $88.4 \%$ (Saunier and Sayed 2006). This accuracy is considered reliable under heavy traffic flow conditions, and should have little impact on the accuracy of the estimated time gaps and speeds. Tracking road users is conducted in two main steps:

1. Camera Calibration: is conducted to identify a mapping between the three-dimensional real world and the two-dimensional image space. Camera calibration is necessary for 
relating road user tracks to real-world positions (Ismail et al. 2013). The calibration process involves the annotation of features in both the video image and orthographic image as shown in Figure $3 a$ and $3 b$

2. Features tracking and grouping: Feature tracking involves tracking distinct points (features) on moving objects. The automated video analysis relies on computer algorithms to differentiate between features of road users and features that are part of the environment (Saunier and Sayed 2006). Features are identified and tracked using an implementation of the well-known Kanade-Lucas-Tomasi feature tracker algorithm. In feature grouping, points that move at similar speed and satisfy other spatial and motion constraints are grouped to create objects, and then the trajectories of these objects are recorded. Figure $3 \mathrm{c}$ and Figure $3 \mathrm{~d}$ illustrate feature tracking and grouping processes.

After obtaining vehicle trajectories, the time gaps and speeds of through vehicles on the major road were detected using the same computer vision tool. Time gap is the time between the front of two successive vehicles exiting a screen, and vehicle speed is the length of a screen divided by the time that the vehicle spent to pass a screen. Virtual screens were added to the video scene at each approach, as shown in Figure 4, to filter through vehicle trajectories, and to record the time when each through vehicle passed the screen. Accordingly, time gaps and speeds of the vehicles passing the screens can be calculated for a large amount of video data. 
Using the computer vision tools, a large sample of time gap and speed data were collected for the two analyzed approaches as shown in Table 1. The lognormal distribution for the time gaps and the normal distribution for the speeds are shown in Figure 5.

A sample of 100 time gaps and speeds was collected manually at the studied approaches to validate the automated data collection process. The comparison between the distributions of the automated and manually collected data showed an accuracy of $96 \%$ and $81 \%$ for the speed and time gaps, respectively. The validation results provide further confidence regarding the feasibility and reliability of the automated process.

\section{Supply Variables}

According to several previous studies (McCoy et al. 1992; Tarawneh and McCoy 1997; Easa and Ali 2005), the available sight distance for left-turn vehicles can be calculated according to equations 9 and 10 .

$S D_{\text {available }}=Y b+Y p-M \min -L w \min / 2$

$Y_{b}=\frac{\left(Y_{a}+Y_{i}\right)\left(X_{r}+\frac{L_{w} m a j}{2}\right)}{X_{i}-X_{r}+X_{O}}$

Figure 6 shows the geometry of available SD (Easa and Ali 2005), where $Y_{b}$ is the sight distance beyond opposing left-turning vehicle, $Y p$ is the longitudinal position of the obstruction, $M \min$ is the median width along minor road, $Y_{a}$ is the SD in advance of opposing left-turning vehicle, $L_{\mathrm{W}}$ 
is the lane width, $Y_{\mathrm{i}}$ is the longitudinal distance from the front of the left-turning vehicle to the driver's eye, $X_{r}$ is the lateral distance of the right corner of the obstruction from the right edge of the opposing left-turn lane, $X_{o}$ is the left-turn lane offset, $X_{i}$ is the lateral distance of driver's eye from the left edge of the left-turn lane. The corresponding parameter values for each approach are provided in Table 2 in case that the opposing obstacle vehicle is a passenger car (PC) (Case 1) or a bus (Case 2). Buses are chosen to represent the heavy vehicles because they are the most frequent type of heavy vehicles on the studied intersection. The PC and bus dimensions were assumed according to AASHTO (2011).

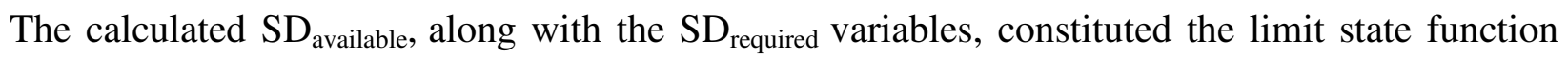
(g) as shown in equation 11 .

$g=S D_{\text {available }}-(0.278 V G)$

\section{ANALYSIS AND MITIGATION}

The FORM analysis was performed using RT software (Mashuli and Haukaas 2013) to evaluate the probability of non-compliance and the sensitivity of the sight distance variables for permitted left-turn movements. Importance sampling analysis was afterwards conducted using the same software to raise the accuracy of the probability of non-compliance results. Figure 7 shows the probability of non-compliance and the sensitivity analysis results for the two approaches.

The probability of non-compliance for sight distance at both approaches was found to increase substantially when the opposing left-turn vehicle is a bus (Case 2), which is expected given the 
larger size of the bus compared to PC. The probability of non-compliance is considerably higher for approach 2 than approach 1 which has a negligible $\mathrm{P}_{\mathrm{nc}}$. This is mainly due to the big offset distance between the left-turn separator and the opposing median $\left(\mathrm{X}_{\mathrm{o}}\right)$ at approach 2 . The results also show that the time gap had higher impact on $\mathrm{P}_{\mathrm{nc}}$ than the speed, which is concluded using the relative importance values shown in Figure $7 \mathrm{~b}$. Importance vectors are calculated using the linearized LSF variance at the design point in standard normal space, as derived in equation 12.

$$
\begin{aligned}
& \operatorname{Var}[\mathrm{G}]=\nabla G^{T} \nabla G \\
& \operatorname{Var}[\mathrm{G}]=\|\nabla G\|^{2} \cdot\left(\alpha 1^{2}+\alpha 2^{2}+\cdots .+\alpha n^{2}\right)
\end{aligned}
$$

Equation 12 shows that the individual components of the alpha-vector serve as indicators of importance, i.e., contribution to the total variance of the corresponding random variables. As a result, the alpha-vector is the primary importance vector for the random variables. The higher absolute value of $\alpha \mathrm{i}$, the more important the random variable $\mathrm{i}$ is.

Two potential strategies can be implemented to reduce the high probability of non-compliance at the second approach. The first strategy is to reconfigure the geometry of the second approach geometry by decreasing the offset distance from the left-edge of the left-turn lane to the rightedge of the opposite left-turn lane. This strategy highly affects the sight distance and can consequently lead to a considerable reduction in the probability of non-compliance (Easa and Ali 2005). Figure 8 shows the probability of non-compliance of the permitted left-turn SD for various left-turn lane offset distances at approach 2 . The figure shows that decreasing the offset distance from $2 \mathrm{~m}$ to $1 \mathrm{~m}$, would decrease the probability of non-compliance by approximately $30 \%$ for PC (case 1) and $20 \%$ for buses (case 2). Another potential strategy is to reduce the speed limit in order to reduce the speed of the through traffic. Figure 9 shows that an average speed 
reduction of $10 \%(\approx 4.50 \mathrm{~km} / \mathrm{hr})$ would lead to a reduction in $\mathrm{P}_{\mathrm{nc}}$ by approximately $6 \%$. The relatively small reduction in the probability of non-compliance makes this strategy less effective, which agrees with the sensitivity analysis results.

\section{CONCLUSIONS}

Assessing the safety impact of geometric design and traffic control features at intersections is usually evaluated using collision modification factors (CMFs). However, the use of CMFs for evaluating the safety impact of permitted left-turn phasing can be challenging due to lack of data and the difficulty isolating the impact of SD which has varying dimensions on collision frequency. Consequently, this paper presents a reliability analysis framework to evaluate the risk of inadequate SD for left-turn vehicles during permitted phasing.

Twelve hours of video data were collected for two approaches at a 4-leg signalized intersection in the city of Surrey, Canada. Automated analysis of the video data was conducted using a computer vision tool to collect speed and time gap data. The probability distributions of the collected speeds and time gaps were established and used along with the intersection geometric data in a reliability analysis framework. Using a reliability analysis tool, the probability of noncompliance $\left(\mathrm{P}_{\mathrm{nc}}\right)$ for $\mathrm{SD}$ was calculated by FORM and Importance Sampling reliability techniques.

The analysis showed that one approach had slight $\mathrm{P}_{\mathrm{nc}}$ for the left-turn sight distance. The second approach showed a high $\mathrm{P}_{\mathrm{nc}}$, which was attributed to the large left-turn offset. The reliability 
analysis also showed that the $\mathrm{P}_{\mathrm{nc}}$ increased at both approaches when the opposing vehicle was a bus compared to a passenger car. Moreover, the sensitivity analysis revealed that the time gap had higher impact on $\mathrm{P}_{\mathrm{nc}}$ than speed. Two potential strategies were proposed to decrease the high $\mathrm{P}_{\mathrm{nc}}$ at the second approach. The strategies included changing the intersection geometry (by reducing left-turn lane offset distance) and speed reduction. The analysis showed that the speed reduction had a small impact on $\mathrm{P}_{\mathrm{nc}}$. A speed reduction of $10 \mathrm{~km} / \mathrm{hr}$ reduced $\mathrm{P}_{\mathrm{nc}}$ by about $13 \%$. On the other hand, the offset strategy had a substantial impact on $\mathrm{P}_{\mathrm{nc}}$; An offset reduction of $1 \mathrm{~m}$ led to a $20-30 \%$ reduction in $\mathrm{P}_{\mathrm{nc}}$.

For further research, the stochastic nature of the variables constituting the available sight distance (e.g. vehicle positions) can be included in the limit state function by accounting for their probability distributions. Moreover, the computer vision tool can be developed to capture the correlation between the data points of the random variables in order to account for it in the reliability analysis. The framework can also be used to assess the risk of inadequate SD for traffic movements other than left turns, and for different phasing configurations. Finally, it is worth noting that $\mathrm{P}_{\mathrm{nc}}$ in this study is not equivalent to the probability of crash occurrence. Rather, it only represents the probability that left-turn drivers do not attain sufficient sight distance to complete their turns safely. A link is still needed to be established between the sight distance $\mathrm{P}_{\mathrm{nc}}$ and the probability of crash occurrence at permitted left turns. Accordingly, safety performance functions that incorporate the probability of non-compliance as a risk measure can be developed using collision data. 


\section{ACKNOWLEDGMENTS}

Financial support from the National Sciences and Engineering Research Council (NSERC) of Canada is greatly appreciated.

\section{REFERENCES}

AASHTO. 2011. AASHTO Green Book - A policy on geometric design of highways and streets. American Association of State Highway and Transportation Officials, Washington, D.C.

Abtahi, S. M. 2011. Analysis and modeling time headway distributions under heavy traffic flow conditions in the urban highways: case of Isfahan. Transport, 26(4): 375-382. doi: 10.3846/16484142.2011.635694.

Davis, G. a. 2007. Safety Effects of Left-Turn Phasing Schemes at High-Speed . University of Minnesota, Minnesota.

Dey, P. P. 2006. Speed distribution curves under mixed traffic conditions. Journal of Transportation Engineering, 132(6): 475-481. doi: 10.1061/(ASCE)0733947X(2006)132:6(475). 
Easa, S.M. 1993. Reliability based design of intergreen interval at traffic signals. Journal of Transportation Engineering, 119(2): 255-271. doi: 10.1061/(ASCE)0733947X(1993)119:2(255).

Easa, S.M. 2000. Reliability approach to intersection sight distance design. Transportation Research Record: Journal of the Transportation Research Board, 1701(1): 42-52. doi: http://dx.doi.org/10.3141/1701-06.

Easa, S. M., \& Ali, M. Z. 2005. Modified guidelines for left-turn lane geometry at intersections. Journal of Transportation Engineering, 131(9): 677-688. doi: 10.1061/(ASCE)0733947X(2005)131:9(677).

Faghiri, A., \& Demetsky, M. J. 1988. Reliability and risk assessment in the prediction of hazards at rail-highway grade crossings. In Transportation Research Record 1160, TRB, National Research Council, Washington, D.C.

Harr, M. 1987. Reliability-Based Design in Civil Engineering. New York: MC Graw-Hill.

Harwood, D. W., Mason, J. M., Brydia, R. E., Pietrucha, M. T., \& Gittings, G. L. 1996. NCHRP Report 383: Intersection Sight Distance. TRB, Natioanl Research Council, Washington D.C.

Hauer, E. 1999. Safety in Geometric Design Standards. Department of Civil Engineering, University of Toronto, Toronto. 
Hou, Y., Sun, C., \& Edara, P. 2012. Statistical test for 85th and 15th percentile speeds with asymptotic distribution of sample quantiles. Transportation Research Record: Journal of the Transportation Research Board, 2279(1): 47-53. doi: http://dx.doi.org/10.3141/227906.

Hussain, A. \& Easa, S.M. 2015. Reliability analysis of left-turn sight distance at signalised intersections. Journal of Transportation Engineering, 142(3): 04015048. doi: 10.1061/(ASCE)TE.1943-5436.0000824

Hussein, M., Sayed, T., Ismail, K., \& Espen, A. V. 2014. Calibrating road design guides using risk-based reliability analysis. Journal of Transportation Engineering, 140(9): 04014041. doi: 10.1061/(ASCE)TE.1943-5436.0000694.

Ibrahim, S. E. B., \& Sayed, T. 2011. Developing safety performance functions incorporating reliability-based risk measures. Accident Analysis \& Prevention, 43(6): 2153-2159. doi: 10.1016/j.aap.2011.06.006.

Ibrahim, S. E. B., Sayed, T. and Ismail, K. 2012. Methodology for Safety Optimization of Highway Cross-sections for Horizontal Curves with Restricted Sight Distance. Accident Analysis and Prevention, 49: 476-485. doi: 10.1016/j.aap.2012.03.016.

Ismail, K., \& Sayed, T. 2010. Risk-Based Highway Design. Transportation Research Record: Journal of the Transportation Research Board, 2195: 3-13. doi: http://dx.doi.org/10.3141/2195-01. 
Ismail, K., \& Sayed., T. 2009. Risk-based framework for accommodating uncertainty in highway geometric design. Canadian Journal of Civil Engineering, 36(5): 743-753. doi: 10.1139/L08-146.

Ismail, K., Sayed, T., \& Saunier, N. 2013. A methodology for precise camera calibration for data collection applications in urban traffic scenes. Canadian Journal of Civil Engineering, 40(1): 57-67. doi: 10.1139/cjce-2011-0456.

Joshua, S. C., \& Saka, A. A. 1992. Mitigation of sight-distance problem for unprotected leftturning traffic at intersections. Transportation Research Record, 1356: 73-79.

Llorca, C., Moreno, A. T., Sayed, T., \& Garcia, A. 2014. Passing sight distance standards based on observational data. Transportation Research Record: Journal of the Transportation Research Board , 2404: 18-26. doi: http://dx.doi.org/10.3141/2404-03.

Mashuli, M., \& Haukaas, T. 2013. Computer program for multimodal reliability and optimization analysis. Journal of Computing in Civil Engineering, 27(1): 87-98. doi: 10.1061/(ASCE)CP.1943-5487.0000204.

McCoy, P. T., Byrd, P. S., Pesti, G., \& Singh, V. A. 1999. Improving sight distance from opposing left-turn lanes. 69th Annual Meeting of the Institute of Transportation Engineer, Washington D.C. CD-006.

McCoy, P. T., Navarro, U. R., \& Witt, W. E. 1992. Guidelines for offsetting opposing left-turn lanes on four-lane divided roadways. Transportation Research Record , 1356: 28-36. 
McGowen, P., \& Stanley, L. 2011. Alternative methodology for determining gap acceptance for two-way stop-controlled intersections. Journal of Transportation Engineering , 138(5): 495-501. doi: 10.1061/(ASCE)TE.1943-5436.0000358.

Melchers, R. E. 1999. Structural Reliability. Ellis Horwood, John Wiley and Sons, Chishester.

Moridpour, S. 2014. Evaluating the time headway distributions in congested highways. Journal of Traffic and Logistics Engineering, 2(3): 224-229. doi: 10.12720/jtle.2.3.224-229.

Ni, Y., \& Li, K. 2014. Estimating rear-end accident probabilities at signalized intersections: a comparison study of intersections with and without green signal countdown devices. Traffic Injury Prevention, 15(6): 583-590. doi: 10.1080/15389588.2013.845752.

Ragland, D. R., Arroyo, S., Shladover, S. E., Misener, J. A., \& Chan, C. Y. 2006. Gap acceptance for vehicles turning left across on-coming traffic: implications for intersection decision support design. Safe Transportation Research \& Education Center.

Richl, L., \& Sayed, T. 2006. Evaluating the safety risk of narrow medians using reliability analysis. Journal of Transportation Engineering, 132(5): 366-375. doi: 10.1061/(ASCE)0733-947X(2006)132:5(366).

Sahoo, P., Rao, S., \& Kumar, V. 1996. Sahoo, P., S. Rao, and V. Kumar. A study of traffic flow characteristics on two stretches of national highway no. 5. Indian Highways, 24(4): 1118. 
Sarhan, M., \& Hassan, Y. 2009. Reliability-based methodology to calculate lateral clearance on three-dimensional alignment. Transportation Research Board 88th Annual Meeting, Washington D.C. No. 09-0977.

Saunier, N., \& Sayed, T. 2006. A feature-based tracking algorithm for vehicles in intersections. The 3rd Canadian Conference on Computer and Robot Vision, Quebec. pp. 59-59.

Saunier, N., \& Sayed, T. 2007. Automated analysis of road safety video data. Transportation Research Record: Journal of the Transportation Research Board, 2019: 57-64. doi: http://dx.doi.org/10.3141/2019-08.

Saunier, N., \& Sayed, T. 2008. Probabilistic framework for automated aAnalysis of exposure to road collisions. Transportation Research Record: Journal of the Transportation Research Board, 2083: 96-104. doi: http://dx.doi.org/10.3141/2083-11.

Schultz, G. A. 2014. Evaluating the safety effects of signal improvements. Transportation Research Record: Journal of the Transportation Research Board, 2435: 19-26.

Srinivasan, R. C. 2012. Crash modification factors for changes to left-turn phasing. Transportation Research Record: Journal of the Transportation Research Board, 2279: 108-117. doi: http://dx.doi.org/10.3141/2435-03.

Tang, K., Kuwahara, M., \& Tanaka, S. 2011. Design of intergreen times based on safety reliability. Transportation Research Record: Journal of the Transportation Research Board, 2259(1): 213-222. doi: http://dx.doi.org/10.3141/2259-20. 
Tarawneh, M. S., \& McCoy, P. T. 1997. Guidelines for offsetting opposing left-turn lanes on divided roadways. Transportation Research Record: Journal of the Transportation Research Board, 1579(1): 43-52. doi: http://dx.doi.org/10.3141/1579-06. 


\section{TABLES}

Table 1 Summary Statistics for Collected Data

\begin{tabular}{ccccccc}
\hline Approach & \multicolumn{3}{c}{ Time Gap $(\mathrm{sec})$} & \multicolumn{3}{c}{ Speed $(\mathrm{km} / \mathrm{hr})$} \\
\hline & $\begin{array}{c}\text { Sample } \\
\text { Size }\end{array}$ & Mean & $\begin{array}{c}\text { Standard } \\
\text { Deviation }\end{array}$ & $\begin{array}{c}\text { Sample } \\
\text { Size }\end{array}$ & Mean & $\begin{array}{c}\text { Standard } \\
\text { Deviation }\end{array}$ \\
\hline 1 & 696 & 5.15 & 3.63 & 614 & 39.55 & 10.41 \\
\hline 2 & 3071 & 4.86 & 4.38 & 2314 & 43.95 & 10.78 \\
\hline
\end{tabular}


Table 2 Available Sight Distance Parameters at the Studied Approaches

\begin{tabular}{ccccc}
\hline & \multicolumn{2}{c}{ Approach 1 } & \multicolumn{2}{c}{ Approach 2 } \\
\cline { 2 - 5 } Parameters & Case (1) & Case (2) & Case (1) & Case (2) \\
\hline $\mathrm{Y}_{\mathrm{p}}$ & $13 \mathrm{~m}$ & $13 \mathrm{~m}$ & $11 \mathrm{~m}$ & $11 \mathrm{~m}$ \\
$\mathrm{M}_{\text {min }}$ & $5 \mathrm{~m}$ & $5 \mathrm{~m}$ & $3 \mathrm{~m}$ & $3 \mathrm{~m}$ \\
$\mathrm{~L}_{\mathrm{W} \text { min }}$ & $3.50 \mathrm{~m}$ & $3.50 \mathrm{~m}$ & $3.50 \mathrm{~m}$ & $3.50 \mathrm{~m}$ \\
$\mathrm{~L}_{\mathrm{W} \text { maj }}$ & $3.50 \mathrm{~m}$ & $3.50 \mathrm{~m}$ & $3.50 \mathrm{~m}$ & $3.50 \mathrm{~m}$ \\
$\mathrm{X}_{\mathrm{o}}$ & $0 \mathrm{~m}$ & $0 \mathrm{~m}$ & $2.00 \mathrm{~m}$ & $2.00 \mathrm{~m}$ \\
$\mathrm{X}_{1}=\mathrm{X}_{\mathrm{r}}$ & 0.435 & 0.20 & 0.435 & 0.20 \\
$\mathrm{X}_{\mathrm{i}}$ & $0.60 \mathrm{~m}$ & $0.40 \mathrm{~m}$ & $0.60 \mathrm{~m}$ & $0.40 \mathrm{~m}$ \\
$\mathrm{Y}_{\mathrm{i}}$ & $1.80 \mathrm{~m}$ & $1.80 \mathrm{~m}$ & $1.80 \mathrm{~m}$ & $1.80 \mathrm{~m}$ \\
$\mathrm{Y}_{\mathrm{a}}$ & $24.20 \mathrm{~m}$ & $17.80 \mathrm{~m}$ & $21.70 \mathrm{~m}$ & $15.30 \mathrm{~m}$ \\
$\mathrm{Y}_{\mathrm{b}}$ & $344.30 \mathrm{~m}$ & $191.10 \mathrm{~m}$ & $23.70 \mathrm{~m}$ & $15.15 \mathrm{~m}$ \\
$\mathrm{ISD}_{\text {available }}$ & $350.55 \mathrm{~m}$ & $197.35 \mathrm{~m}$ & $30 \mathrm{~m}$ & $21.40 \mathrm{~m}$ \\
\hline
\end{tabular}




\section{FIGURE CAPTIONS}

Figure 1 Framework for Reliability Analysis of Permitted Left-Turn Sight Distance

Figure 2 Illustration of Left-turn SD: (a) Google Image of the Left Turns, Through Traffic, Obstacle Vehicles Positions, and the Camera Positions (red circles) at the Studied Approaches

(b) Video Image of a Left-Turn Collision

Figure 3 (a) and (b) Camera Calibration (c) Feature Tracking (d) Feature Grouping

Figure 4 Trajectories Screening

Figure 5 Time gap and Speed Distributions: (a) time gap and (b) speed distribution

Figure 6 Geometry of the Available Sight Distance

Figure 7 Reliability Analysis Results (a) Probability of non-compliance (b) Variables' Sensitivity

Figure 8 Probability of Non-compliance versus Left-Turn Lane Offset at Approach 2

Figure 9 Probability of Non-compliance versus Speed Reduction at Approach 2 


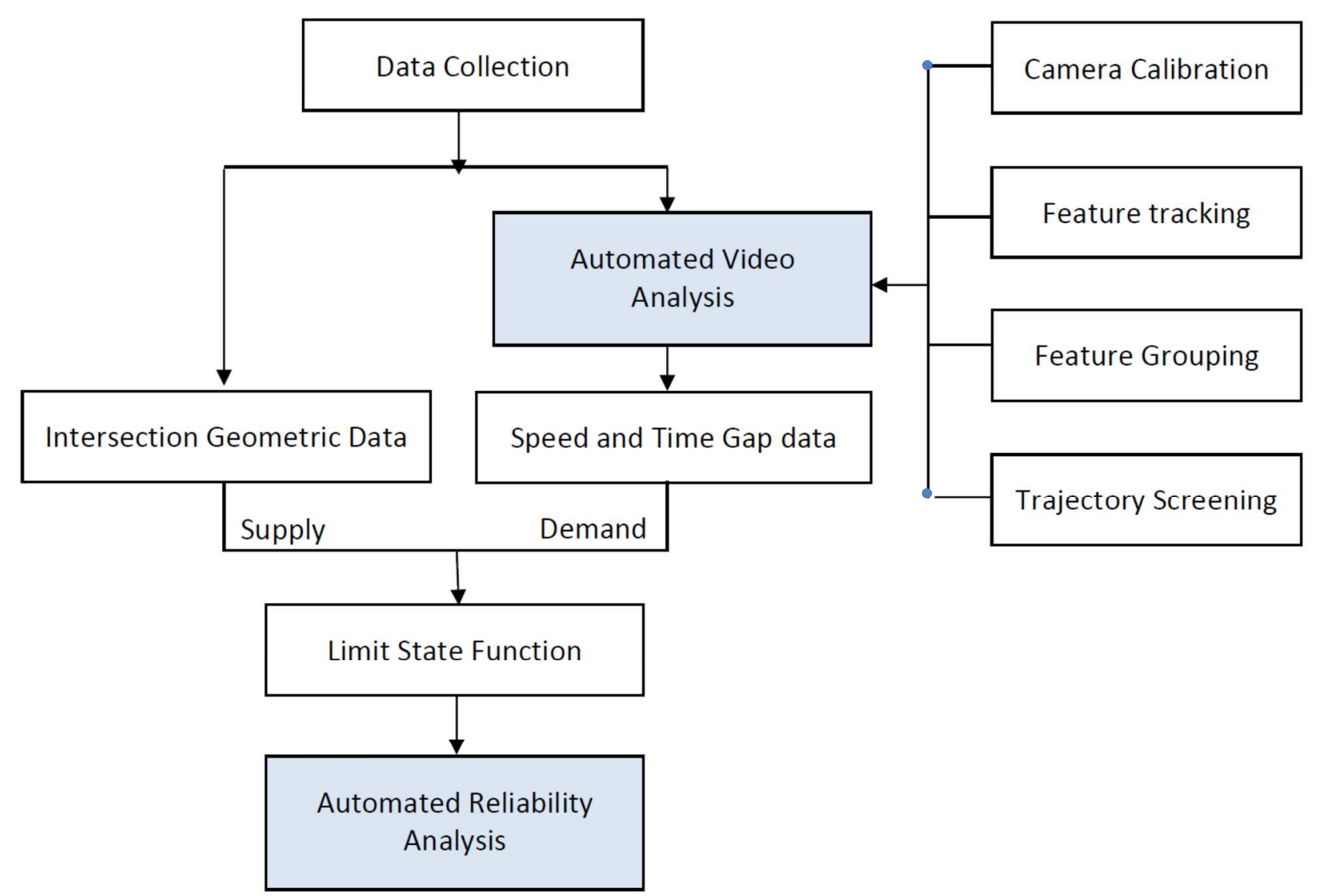




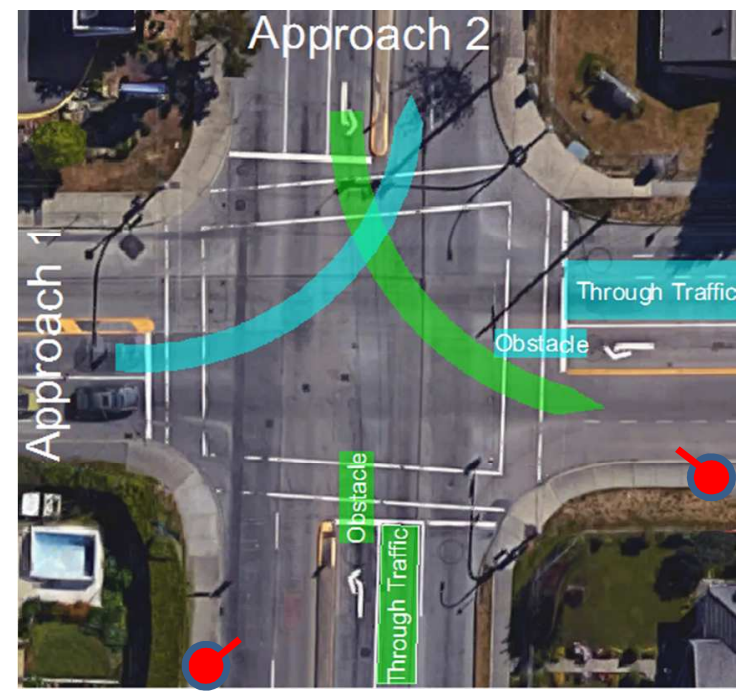

(a)

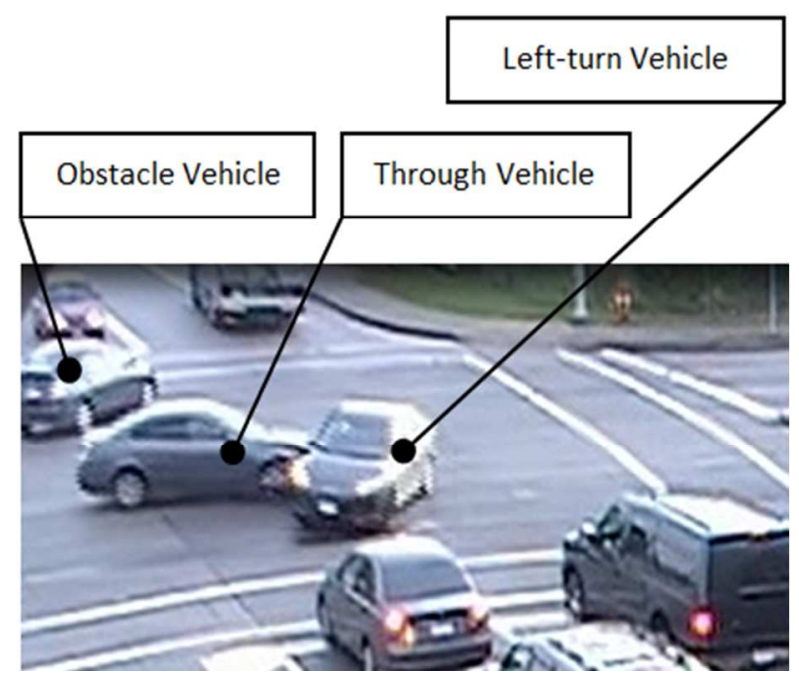

(b) 


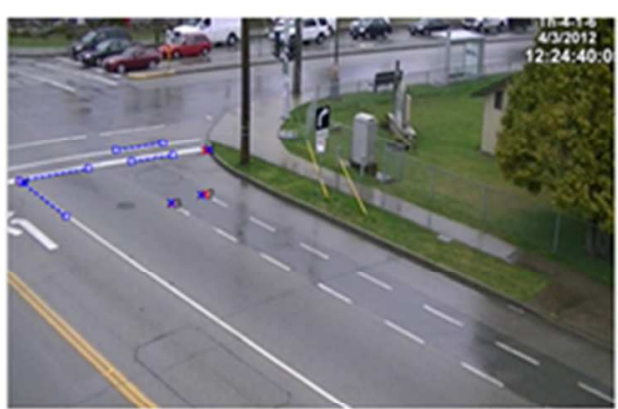

(a)

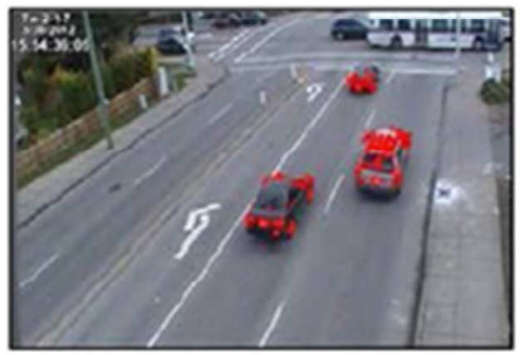

(c)

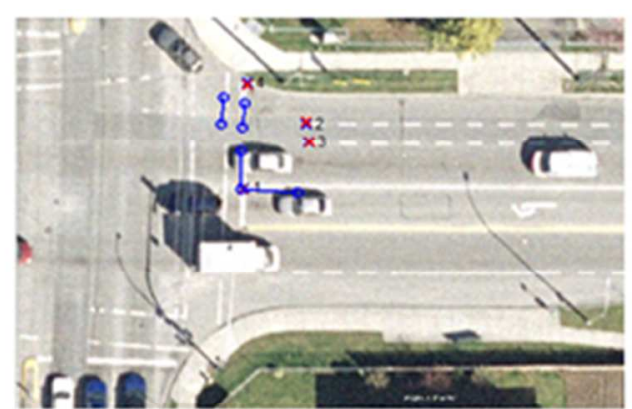

(b)

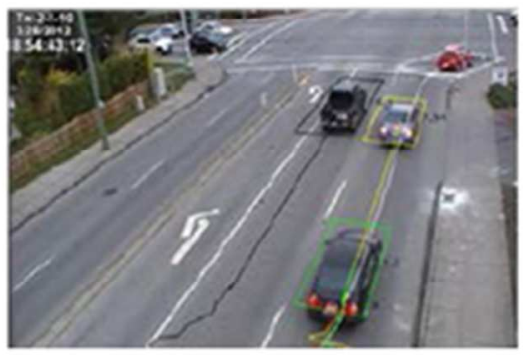

(d) 


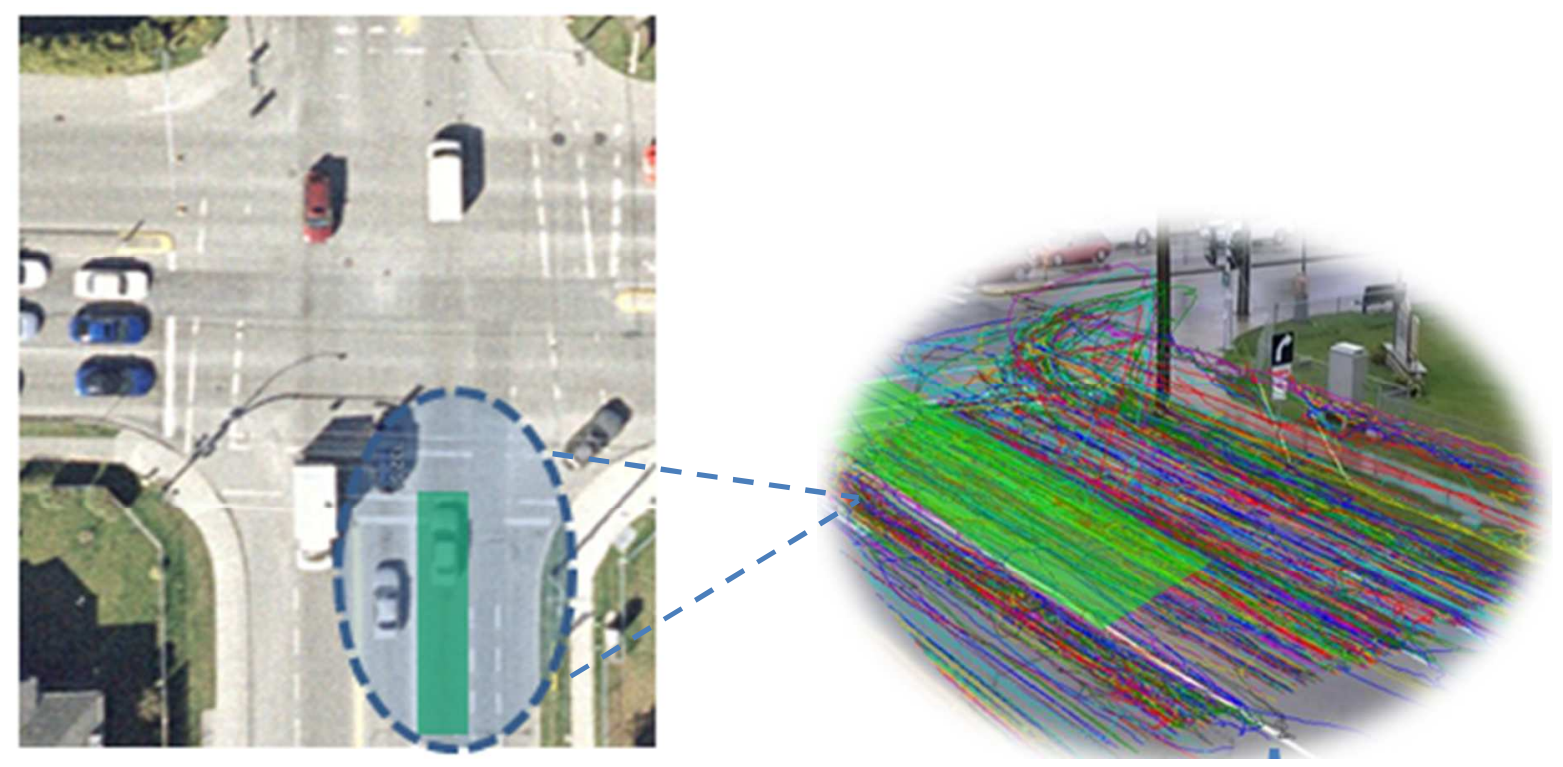




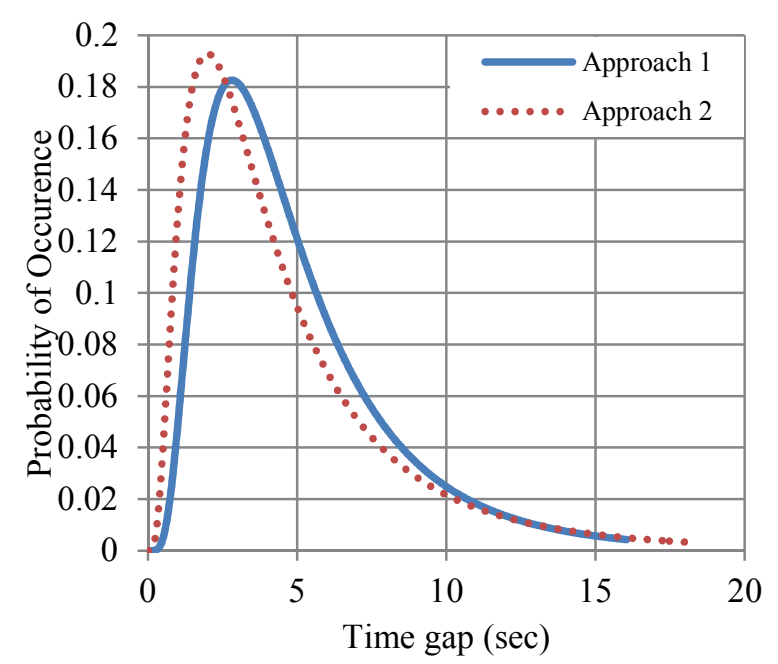

(a)

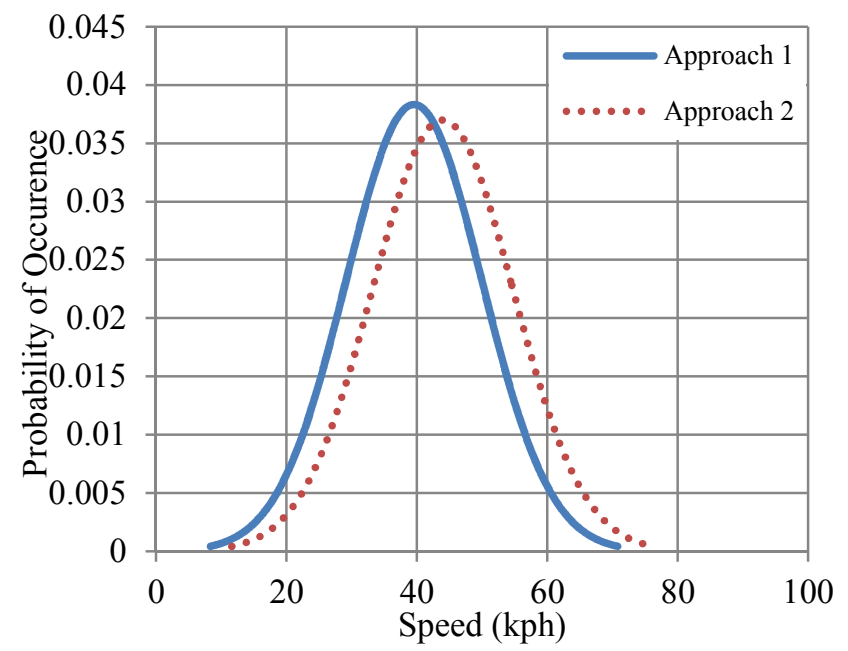

(b) 


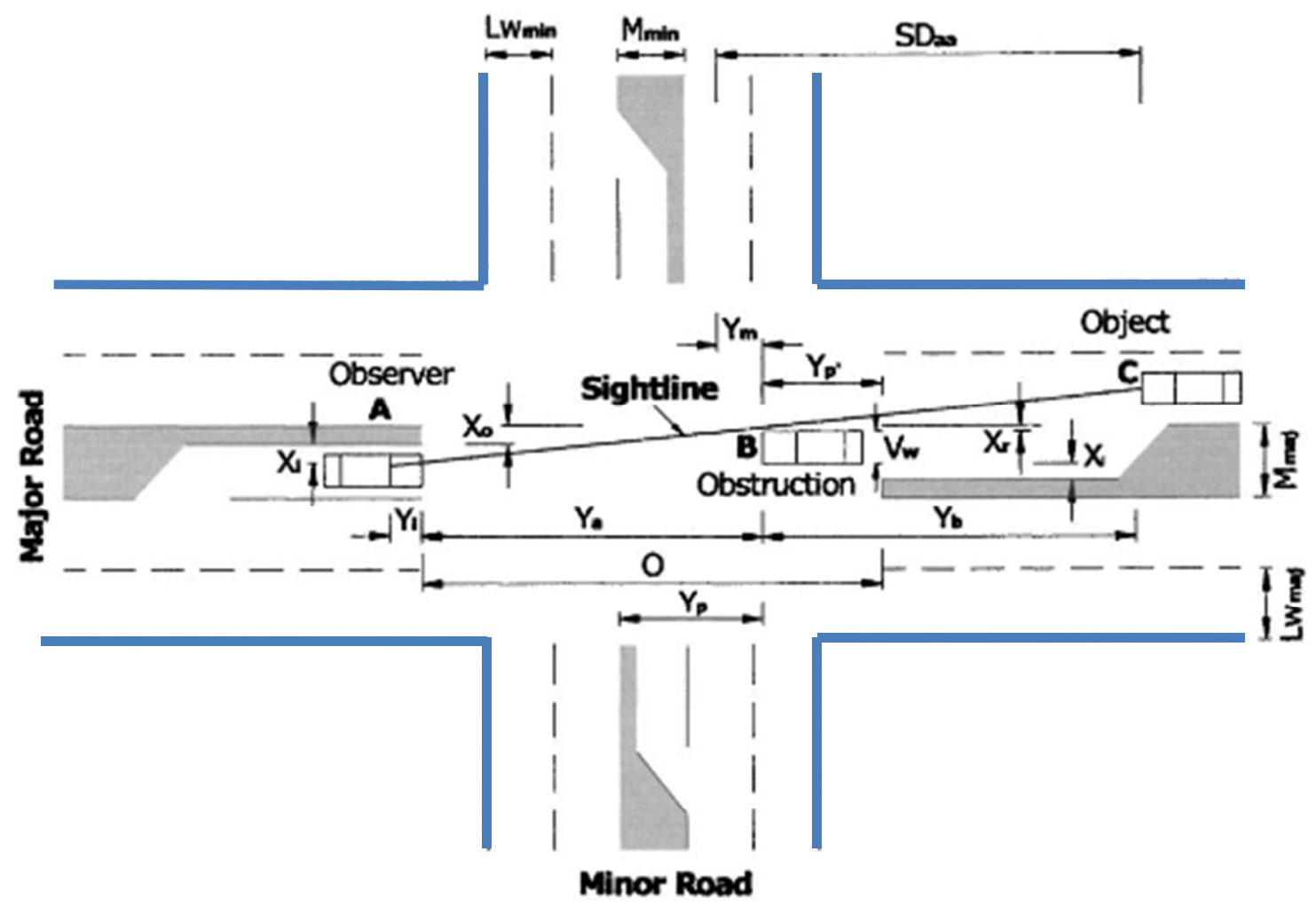




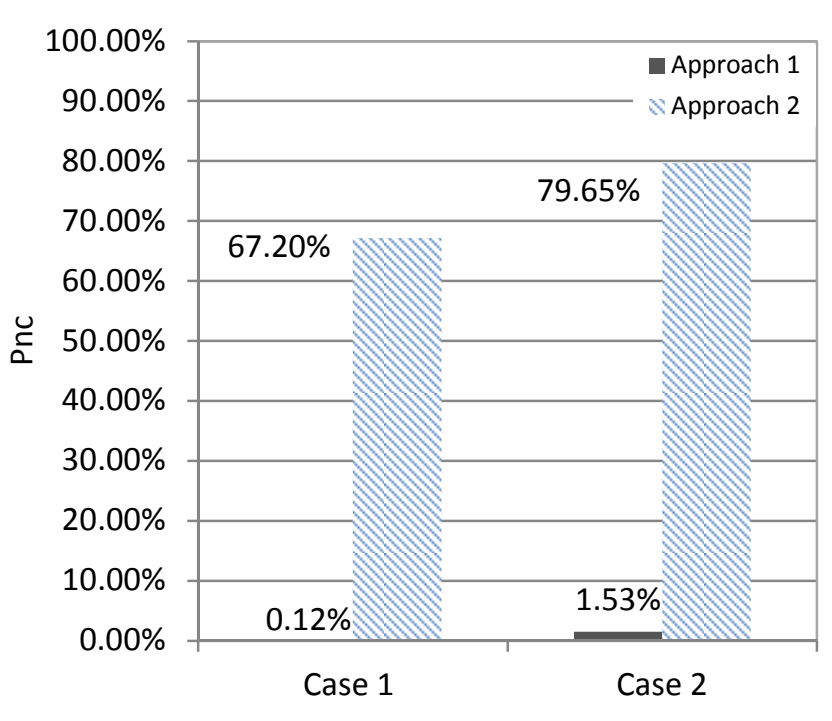

(a)

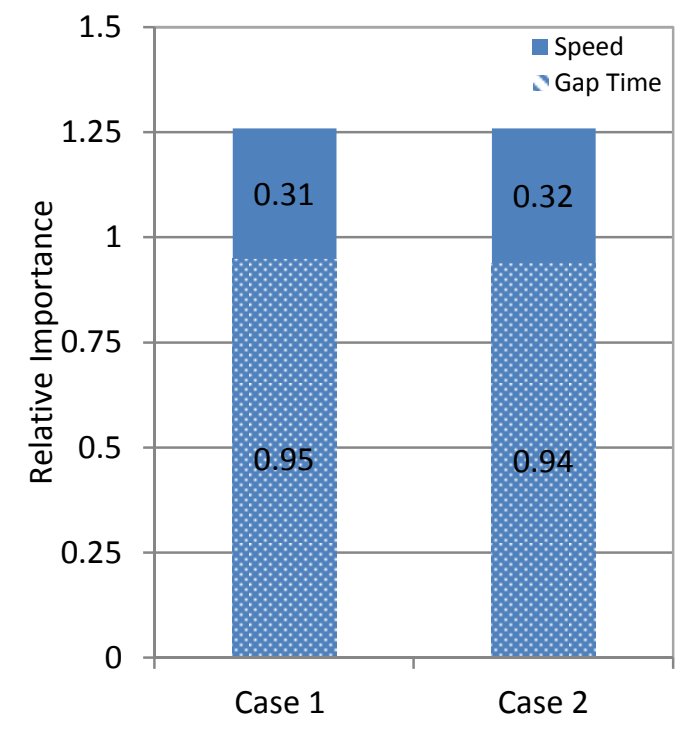

(b) 


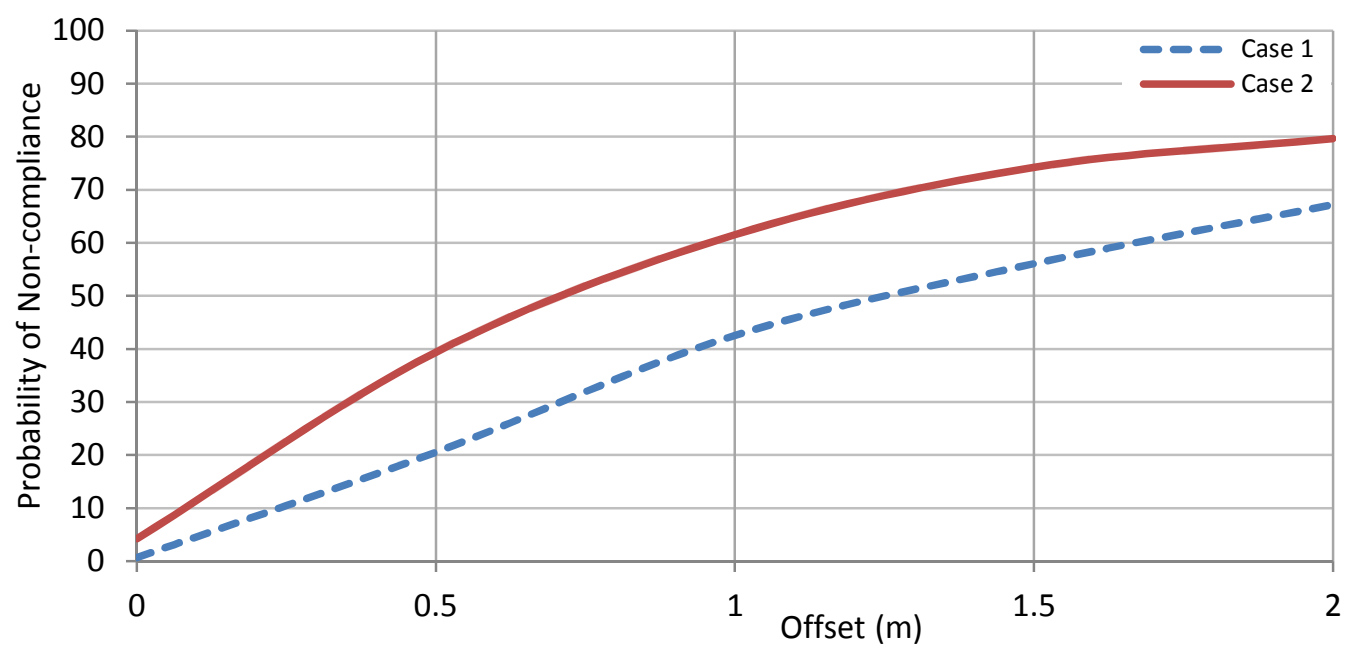

https://mc06.manuscriptcentral.com/cjce-pubs 


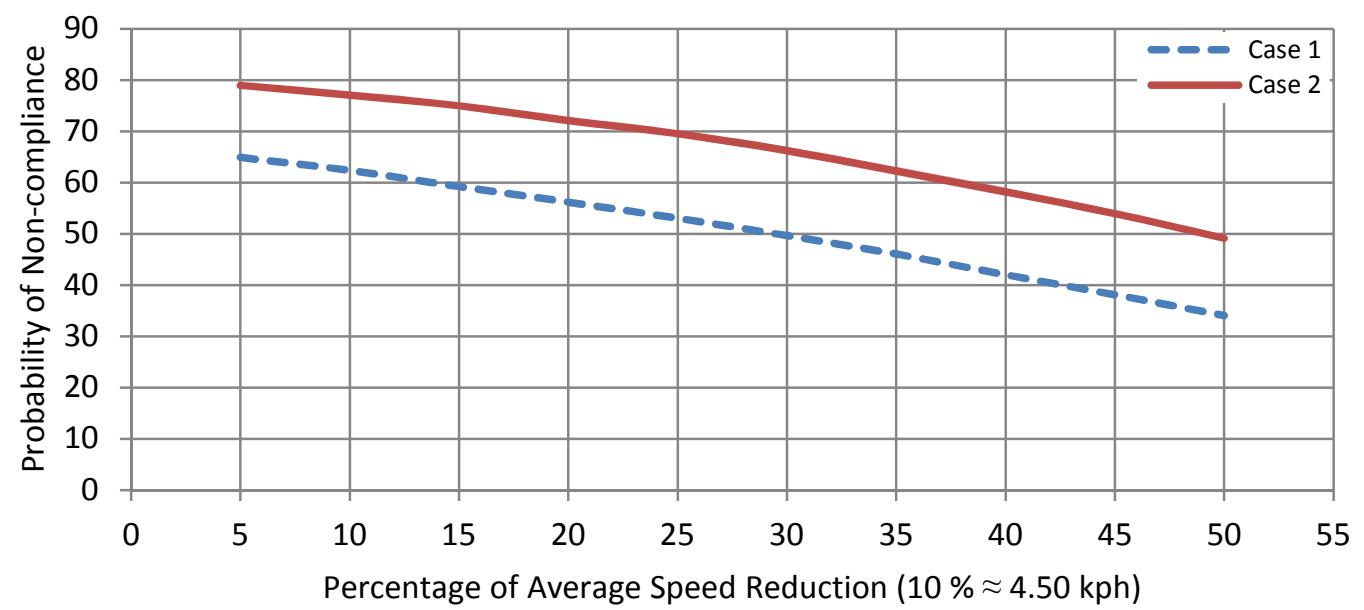

https://mc06.manuscriptcentral.com/cjce-pubs 